\title{
Different editor, same mission
}

\author{
Lodovico Balducci - M. M. Ferrario
}

Published online: 16 March 2012

(C) Springer-Verlag 2012

It is a pleasure for me to announce that Professor Lodovico Balducci, leading oncologist who actively and continuously contributed in these years as Associate Editor for improvement of the journal, has been appointed as Editorin-Chief.

I wish here to recall his scientific coordination of the reviews on quality of life/sense of life and more recently on personalized medicine. For the present year we will share the editorial direction of the journal.

I am glad that the journal in these years has got more credits among physicians, nurses, and health care providers, and I consider this rearrangement in the chief editorial board a further step for spreading and increasing the appealing of the journal in the scientific community.

Marco M. Ferrario

Editor-in-Chief.

"It is the consensus that life begins with personhood." told me a colleague during a cafeteria discussion about abortion rights. This otherwise bright young man did not realize that he was undermining his own argument in favor of abortion. By highlighting personhood he declared the sanctity and therefore the inviolability of each and every human life!

Personhood is one of those constructs that cannot be confined by words, the same way that the wind cannot be trapped and the fire cannot be harvested. Personhood is the

L. Balducci $(\bowtie) \cdot$ M. M. Ferrario

Senior Adult Oncology Program, Miami, FL, USA

e-mail: Lodovico.Balducci@moffitt.org

M. M. Ferrario

Varese, Italy personal experience of being alive, i.e., of being unique, because each person recognizes to be endowed with unique talents. These purport a unique mission that provides a person with a unique identity which is the source of that person's dignity i.e., sacredness. The word dignity derives from the Latin "dignus" that means worthy and deserving. Personhood implies that each person is endowed with dignity as a birth right, i.e., every person deserves to be afforded all the opportunities to accomplish his/her mission, to pursue his/her unique call.

Our times are ambivalent toward the person. On one side personal values such as autonomy and justice are emphasized as the backbone of freedom that any democratic society cherishes. On the other side, an ever more complex societal organization supports the classification of individuals according to measurable characteristics. This necessity tends to suppress personhood that by definition cannot be measured. In a hurried and busy society such as ours it is easy to see persons as units of the same assembly line, or the same waiting line of an airport or of a shopping mall, and to forget that each one of those units is unique and find himself/herself in that common line for a unique and diverse reason. Rather than ants hoarding the same food, rather than bees secreting the same honey until the end of times, persons enrich their consortium with each other's creativity, an endeavor that is called progress.

The Journal of Medicine and the Person was born out of this precise necessity to preserve the centrality of the person in the practice of an increasingly technological medicine where the opportunity for personal interactions are becoming progressively more reduced, where both patients and providers risk to become units of different and sometimes competing assembly lines. The journal wants to make sure that the outstanding medical advances of our times are of service to the person, i.e., they empower the person to 
exercise his/her freedom, to accomplish his/her unique mission. The journal reflects the inspiration of a movement that began in Milan, has now adherents in several different towns within and outside Italy. My first job as Editor-inChief will be to harness these resources from around the world and to create an international forum accommodating all the riches of a multicultural society.

Under the directions of the two previous Editors-inChief, Giancarlo Cesana and Marco Ferrario, the journal has defined its role and its position and has built a lasting reputation. To both of them I send my heartfelt thanks, my sense of deep appreciation for the proclamation of the human person and a humble request for help in my new role. I hope that with their support and prayers I will be worthy to wear their shoes in this challenging task. In particular, I am grateful to Marco Ferrario for having accepted to remain the Editor-in-Chief during the transition and to afford me the opportunity to become accustomed to the preparation of the journal. I hope he will continue enriching the editorial board with his outstanding talents.
I wish to conclude my introduction with a call to our readership. I need to hear from you. First of all I need to hear what we can do to fulfill more completely our mission. Second I need to receive accounts of your experiences as physicians, students, nurses, and health professionals to identify the challenges to the maintenance of the person in your profession and in your growth. I will welcome articles that describe these experiences and outline the challenges ahead of us. Third, I need to hear from your patients, to learn from them whether they feel that their stories are represented in our publication, to receive their input on how we can best help to preserve their personhood during the disease ordeal.

You are welcome to contact me by mail at the journal published or by email. Lodovico.Balducci@moffitt.org and lbalducci@aol.com.

I hope to hear from you very soon.

Lodovico. 